This is the author's Post-print version (final draft post-refereeing as accepted for publication by the journal). The definitive, peer-reviewed and edited version of this article is published as: Mulder C.H. and van Ham M. (2005) Migration histories and occupational achievement. Population, Space and Place 11(3), 173-186. http://dx.doi.org/10.1002/psp.365

\title{
Migration Histories and Occupational Achievement
}

\section{Clara H. Mulder* and Maarten van Ham ${ }^{* *}$}

*University of Amsterdam, Department of Geography, Planning and International Development Studies, Nieuwe Prinsengracht 130, 1018 VZ Amsterdam, The Netherlands, Phone: +31 20-525 4014/4063, Fax: +31 20-525 4051, E-mail: C.H.Mulder@uva.nl

** Utrecht University, Faculty of Geosciences, Urban and Regional research centre Utrecht (URU), P.O. Box 80.115, 3508 TC, The Netherlands, Phone +31 (0)30 253 1370/1399, Fax +31 (0)30 253 2037, E-mail: m.vanham@ geog.uu.nl

Abstract. We have investigated the impact of men's and women's migration histories on their occupational achievement. Compared with previous work, our operationalization of migration histories is much more detailed: we include not only the distinction between onward and return migration, but also the crucial aspects of the destination and short-term versus long-term effects of migration. Using retrospective survey data for the Netherlands and a least-squares regression model of socio-economic status, we explain the socio-economic status of men and women in a given year from the migration history up to that year, controlling for other factors known to influence socio-economic status. Support was found for the hypothesis that migration has a positive long-term impact on men's occupational achievement. Only multiple migrations affect women's occupational achievement significantly, in a positive way.

Keywords: migration, migration history, occupational achievement, socio-economic status, gender differences, life course

\section{Introduction}

Since Sjaastad (1962) argued that migration should be viewed as an investment in human capital, numerous studies have investigated the economic gains accruing from migration experienced by individuals and households. There are two reasons why people should benefit from migration. First, those who have migrated have extended their job search area, enabling them to choose from a greater number of jobs compared with those who only search for jobs on the local labour market. Second, those who have migrated to a particular destination are able to profit from the educational and labour market opportunities at that destination. To experience the benefits from migration, people should be willing to make the sacrifices accompanying migration, and so, to select themselves into the category of migrants. 
There has been ample research into the economic gains accruing from migration covering a certain distance within countries. Most of this research has shown that men who migrate between labour markets indeed tend to do better occupationally than those who do not, but such gains are not necessarily enjoyed by women (Bonney \& Love, 1991; Jacobsen \& Levin, 1997; Smits, 2001, for example).

It has also been shown that the destination of migration matters. The gains are likely to be greater if a move is directed to an area with ample educational and labour market opportunities: typically, a country's larger cities (Blau \& Duncan, 1967). Within the UK, migration to the South East of England (including London) particularly favours upward social mobility (Fielding, 1992). The Paris region serves a similar function in France (Lelièvre \& Bonvalet, 1994).

Most studies have focused on the impact of migration on occupational achievement immediately after the move. An important, but under-researched issue is the extent to which the impact of migration lasts for a longer period in the life course. From the scarce literature that draws a distinction between the short-term and longerterm impacts of covering a distance by migration, we know that the negative impact of migration on women's labour market positions tends to fade in the course of a few years (Spitze, 1984; Clark \& Davies Withers, 2002). Over an even longer term, one could expect a useful benefit from having moved to an area with favourable opportunities. An indication that such a long-term benefit indeed exists can be derived from Van Ham's (2003) finding that those who live in an area with ample job opportunities on labour market entry have better chances of obtaining a high socio-economic status later in life than those who do not.

Furthermore, most existing studies have focused on the impact of just one migration: the most recent one. However, there is reason to suspect that not only does the most recent migration matter, but also migrations that took place earlier in the life course. An indication of the importance of earlier migrations can be derived from the literature focusing on the difference between onward and return migration. The results of this work suggest that, at least for men, onward migration yields greater gains than return migration (Bailey \& Cooke, 1998; Cooke \& Bailey, 1999; Newbold, 1996). This finding indicates that migration experience encompassing a variety of regions are more favourable to occupational achievement than migration experience in a more limited number of regions.

In this paper, we have addressed the following research question: What is the impact of the migration histories of men and women on their occupational achievement? Compared with previous work, our operationalization of migration histories is much more detailed: not only do we include the distinction between onward and return migration, but also the crucial aspects of the destination and the short-term versus longterm effects of migration.

Using retrospective survey data for the Netherlands, we explain men's and women's socio-economic status in a given year from the migration history up to that year, controlling for other factors known to influence socio-economic status (level of education, age, and household situation, for example). Migration histories are classified according to three criteria: whether they include a long-distance move; whether they include a period in a large city; and whether any repeat move was an onward move, or a return migration. We have used a least-squares regression model of socio-economic status for person-years while correcting for the clustering of person-years within respondents. 


\section{Theory and research background}

\section{Short-term and long-term gains from migration}

According to Sjaastad (1962), migration should be seen as an investment in human capital. Because of this investment character of migration, people should, in general, be more successful on the labour market after migration than they were before. By showing a willingness to migrate people enlarge their job search area, thereby creating the opportunity to consider many more job opportunities than would have been the case had they restricted their job search to the immediate surroundings of their current residential location. By using these opportunities, migrants are able to make more progress in their labour market careers than non-migrants.

This simple picture of the positive impacts of migration has long been challenged by findings from the literature on family migration. From this literature, the picture emerges that migration, although beneficial for men, tends to have a negative impact on women's labour market careers (for an overview, see Cooke, 2003). This difference is thought to occur because women are more likely than men to move as 'tied movers', or 'trailing partners'. At the same time, women are less likely to push through a family move for the sake of their own careers than men are (Smits, Mulder \& Hooimeijer, 2003).

The investment character of migration leads to the expectation that migration pays off in the long term, although not necessarily in the short term. By migrating, a worker may speed up the accumulation of human capital. If it takes place in the early stages of the labour-market career, this accumulation may lead to particularly beneficial long-term advantages compared with people who do not migrate (Topel \& Ward, 1992). Even those who migrate with their wives or husbands might experience a long-term benefit from the move if it is directed towards an area with favourable job opportunities. Yet, nearly all studies on the gains and losses associated with migration concentrate on the short-term effects of migration: the gains or losses are observed a short period after the move. Some studies are cross-sectional, focusing on differences between migrants and non-migrants and observing the labour market characteristics of migrants and nonmigrants only after a potential move (Smits, 2001, for example). Others use longitudinal data, and compare the labour market characteristics of migrants and non-migrants before and after a potential move (Cooke, 2003, for example). A few studies pay attention to the possible changes in the negative impact of migration on women's labour market achievement during the course of time after the migration has taken place. These studies find that this negative influence has tapered off in one to three years' time from the migration (Clark \& Davies Withers, 2002; LeClere \& McLaughlin, 1997; Spitze, 1984). It is possible that the long-term effect of migration on women's labour market achievement may be positive even though the short-term effect is not. Evidence from West Germany, however, seems to suggest that migration has a negative impact for women even in the longer term. In Wagner's (1989) study of the impact of migration on labour market achievement, migration was defined as changing residential location between the age of 15 and the moment of observation. Wagner found that, for women, migration had a negative effect on the likelihood of upward job mobility, but a positive effect on the likelihood of downward job mobility. For men, the effects were the reverse.

All in all, we hypothesised that, for men, migration histories with long-distance moves lead to better occupational achievement in the long term, compared with 
histories without long-distance moves. Whether this gain also holds for women was difficult to predict.

Because many migrations are undertaken with the deliberate aim of making progress in the occupational career, the relationship between migration histories and occupational achievement is not strictly causal. We return to this issue at the end of the Theory section.

\section{Gains from onward and return migration}

A well-known finding from the migration literature is that having migrated previously is a major factor enhancing the likelihood of further moves (DaVanzo, 1981; Morrison, 1971). Many of the repeat migrations are return moves (DaVanzo, 1981). There are several reasons for expecting differences in the gains accruing from onward moves and those from return moves. First, some of the return moves are corrective moves, made after the migrant has been disappointed in the opportunities offered by the location to which the initial move was directed (Bailey \& Cooke, 1998; DaVanzo, 1981; Newbold, 1996). Second, some of the return moves are likely to be motivated by such noneconomic factors as childrearing and caring for the elderly (Bailey \& Cooke, 1998). Both these characteristics of return moves lead to the expectation that return movers do less well occupationally than onward movers. Newbold (1996) indeed found that return migrants in Canada were negatively selected and tended to experience lower wage levels than onward migrants. One can also argue that, unlike return movers, onward movers display a willingness to extend their job search area in a manner similar to that of first-time migrants. Consequently, they pick their job opportunities from an even greater variety of regions than first-time or return migrants.

On the other hand, return movers may profit from the location-specific capital they have left behind in their original place of residence (DaVanzo, 1981) and may use pre-established local information or child-care networks (Bailey \& Cooke, 1998). So, in some cases it might be easier to find an appropriate job after a return migration than after an onward migration. Interestingly, Bailey and Cooke (1998) found that, in the United States, wives had better chances of full-time employment after return migration than after onward migration, whereas among men, onward migrants did better than return migrants.

The cited studies that report a difference between return and onward movers have all measured the short-term effect of the repeat moves. In the long term, the gender differences in the impact of return versus onward moves might change. Our hypothesis was, therefore, that for men, migration histories with an onward migration lead to better occupational achievement than migration histories with a return migration. For women, the difference between onward and return migration may be either smaller or reversed.

\section{Gains from living in larger cities}

In today's post-industrial economies, the greatest concentrations of jobs and educational institutions are still located in large cities. These therefore offer the best opportunities for upward social mobility and for the accumulation of human capital (Blau \& Duncan, 1967; Wagner, 1989; Simpson, 1992).

Following the same line of reasoning as for migration as such, we can expect migration to or near a large city to pay off in the long run, even after the city has again been left. A stay in the London or Paris region indeed seems to pay a long-term dividend (Fielding, 1992, for London; Lelièvre \& Bonvalet, 1994, for Paris). For the 
Netherlands, Van Ham (2003) found a long-term positive impact of having lived in an area with ample labour market opportunities in the period of labour market entry. This impact of the residential location at the time of labour market entry was found to become stronger rather than fade over the life course. Van Ham's (2003) interpretation of this finding was that workers who start their careers from a location with favourable opportunities set accumulate human capital more quickly and get a head start over other workers in less favourable labour markets. This head start gives workers the opportunity to accumulate human capital more rapidly and increase their lead. We therefore hypothesised that migration histories with a period in a large city are associated with better occupational achievement in the long term, and that this was possibly more so for men than for women.

An interesting further argument concerning the role of large cities in migration histories stems from Fielding's (1992) concept of escalator regions. Fielding argues that the South East of England acts as an escalator region within the UK, in the sense that this region attracts potentially upwardly mobile migrants; migration to this region favours upward social mobility, and a substantial share of the in-migrants leave the region later in life in order to profit from the returns on the investment of a sojourn in the region. This is not to say that a stay in an escalator region causes upward mobility; rather, the escalator region offers good opportunities to those who are willing to migrate to the region. The escalator region argument suggests that those who succeed in moving on to pursue their careers outside the large city are even more successful occupationally than those who feel the need to stay in the city. In line with this argument, we hypothesised that migration histories passing through, but ending outside a city are associated with better occupational achievement than migration histories ending in a city.

\section{Synthesis: the influence of type of migration history on occupational achievement}

Our hypotheses pertain to three aspects of a migration history: whether or not it contains a migration covering a certain distance; whether or not it contains an episode in a large city - or more precisely, a move to a large city and/or away from a city; and whether it contains any return or onward move. These aspects can be combined into a single classification of migration histories encompassing nine types (see also Figure 1): (1) histories without (long-distance) migration and without an episode in a large city (nomignocity); (2) histories without migration and with an episode in a large city (nomigcity); (3) histories with one migration and without an episode in a large city (onemignocity); (4) histories with two or more migrations including at least one return migration, and without an episode in a city (returnnocity); (5) histories with two or more migrations, all onward, and without an episode in the city (onwardnocity); (6) histories with one migration, directed to a large city (tocity); (7) histories starting in a large city and a migration from that city (fromcity); (8) histories with two or more migrations including at least one return migration, and with an episode in a city (returncity); (9) histories with two or more migrations, all onward, and with an episode in a city, (onwardcity).

Given the above hypotheses, a certain hierarchy could be expected in the degree to which these nine types of migration histories were associated with occupational achievement. This hierarchy is depicted in Figure 2. The first principle in the hierarchy is that migration should lead to better occupational achievement. For that reason, types 3 , 4, and 5 (each with migration but without an episode in a city) should be more 
favourable than type 1 (nomignocity); and types 6 through 9 (each with migration and with an episode in a city) are more favourable than type 2 (nomigcity).

The second principle is that an episode in a city should lead to better occupational achievement. For that reason, type 2 (nomigcity) should be more favourable than type 1 (nomignocity); types 6 and 7 (each with a migration and an episode in a city) should be more favourable than type 3 (onemignocity); type 8 should be more favourable than type 4 (both contain a return move, but only type 8 contains an episode in a city); and type 9 should be more favourable than type 5 (both contain an onward move, but only type 9 contains an episode in a city).

The third principle is that onward moves should lead to better occupational achievement than return moves. For that reason, type 5 (onwardnocity) should be more favourable than type 4 (returnnocity); type 9 (onwardcity) should be more favourable than type 8 (returncity).

Because we did not know how migration compared with living in a large city, we could not formulate hypotheses about the relative positions of types 2 and 3 and the position of types 6 and 7 compared with types 4 and 5. Because an extra move might be made to correct a previous move (the outcome of the first move was not what they expected), it is also unclear how types 4 and 5 compare to type 3 and how types 8 and 9 compare to types 6 and 7.

$<$ Figure 1 about here>

$<$ Figure 2 about here>

\section{A note on causality and self-selection}

An important part of the mechanisms through which migration histories affect occupational achievement is self-selection. As several authors have argued, migrants are a self-selected category of people, many of whom are more motivated to achieve occupationally than non-migrants (Cooke \& Bailey, 1996, 1999; Newbold, 1996; Smits, 2001). In an economist's terms, the decision to migrate is partly endogenous to the decision to take up a better job. So, one may state that migration is not the cause of occupational achievement, but an instrument that leads to occupational achievement (compare Van Ham, 2001).

In the studies by Cooke and Bailey (1996, 1999), Newbold (1996), and Smits (2001), efforts have been made to correct for the self-selectivity of migrants, with the aim of disentangling self-selectivity from causation. By making this correction, the authors attempt to estimate the 'true' effect of migration: that is, the effect a migration would have if the migrants had in other respects the same characteristics as nonmigrants.

We have chosen not to correct for the self-selectivity of migrants, for the following reason. The fact that migrants select themselves and deliberately choose to move in order to achieve better in occupational respects is an essential part of the process we wanted to study. We wish to see to what extent the investment people make by migrating pays off in later life. By correcting for self-selection, we would rule out the deliberate choice of making this investment and would run the risk of losing sight of the connection between investment and payoff. The consequence of this choice is that, strictly speaking, our regression models cannot be regarded as causal models. Rather, 
they should be seen as sophisticated descriptive statistics (Aassve, Mazzuco \& Mencarini, 2003).

It should be noted that the problem of self-selection addressed here is not the classical problem of sample selection bias. The problem of sample selection bias may occur when the dependent variable in an analysis is not observed for a certain category of the population while the expected value of that dependent variable differs systematically from the category that is observed and is thus part of the sample. This problem does not occur for migrants versus non-migrants: they are both part of the sample. We do in fact have a possible problem of sample selection bias, because we only observe the occupational status of those in a job, but not of the non-employed. We will address that problem in the Data and Methods section.

\section{Other factors influencing occupational achievement}

In the analyses, we have controlled for a number of factors that are known to influence occupational achievement. Based on previous research, we expected that, with rising age, people make progress in their labour-market careers and improve their socioeconomic status. Those with a higher level of education are expected to reach a higher socio-economic status. In periods of non-employment the accumulation of labourmarket experience is interrupted, so the number of years in which a respondent was not employed is expected to influence occupational achievement negatively. Among women in the Netherlands, the presence of children in the household, particularly those below school age, often leads to a change from fulltime to part-time employment (Fagan \& Rubery, 1996). It was expected that, for women, the presence of young children would influence occupational achievement negatively. Finally, it was expected that because of changes in the economic climate obtaining a high socio-economic status would be easier in some periods than in others.

\section{Data, measurement, and method}

\section{Data}

The data were derived from three retrospective life-course surveys for the Netherlands, each containing data on the household career, educational career, labour-market career, and housing career. The first is the SSCW survey (ESR/STP, 1992) ${ }^{1}$. The second and third are the 1993 and 2000 Netherlands Family Surveys (NFS; Ultee \& Ganzeboom, 1993; De Graaf et al., 2000). All three datasets contain information that is roughly representative of the Netherlands population aged 18-65 as of 1992 (SSCW; around 3000 respondents), 1993 (NFS 1993; 1000 respondents), or 2000 (NFS 2000; 850 respondents) respectively. The sets were pooled in order to obtain a large sample size. The vast majority of the respondents were native-born.

For the analysis, we selected person-years, starting from 1946, in which the respondents were aged between 25 and 60, lived in the Netherlands, and were in paid employment. Age 25 was chosen to ensure that the respondents had most probably left

\footnotetext{
${ }^{1}$ The survey was commissioned by the Stichting Sociaal-culturele Wetenschappen (SSCW), Nederlandse Organisatie voor Wetenschappelijk onderzoek (NWO). The dataset is available under the title 'Aspects of life-event history of the Dutch population: part 1: changes in socio-demographic data, social mobility, relationships history, educational career, and work mobility' at the Niwi Steinmetz archives (under number P1107).
} 
fulltime education and had left the parental home. Age 60 was chosen because the proportion still in the labour force after the age of 60 is low in the Netherlands. Those who experienced periods of non-employment as well as employment contributed all person-years they were employed. There were no other reasons for periods of nonobservation except missing values on crucial variables, which were rare. This procedure resulted in 47,530 person-years belonging to 3188 respondents.

\section{Measurement}

The dependent variable is occupational achievement for each valid person-year. It was measured as the socio-economic status of the current job in the year of observation, according to the International Socio-Economic Index of occupational status (ISEI; Ganzeboom et al., 1992). The ISEI ranges from 10 to 88. The ISEI scores were divided by 10 so that the parameter estimates could be read easily. The ISEI was updated each time a respondent changed jobs or employment status. It should be noted that the ISEI does not fully account for differences between labour market segments in opportunities for making career progress. Also, for some occupations the ISEI does not very well recognise differences between juniors and supervisors. However, for many other occupational categories ISEI does have separate scores for those who have climbed the possible career ladder within a certain sector. We therefore think the ISEI provides a reasonable indicator for career advancement, even though this advancement is probably underestimated for part of the respondents.

The major independent variable is 'type of migration history'. Nine types were distinguished (see Theory section and Figure 1). 'Cities' are the eight agglomerations depicted in Figure 3. Each of these eight cities has at least 100,000 inhabitants and is a major centre of higher education and/or high-level jobs. An 'agglomeration' is a city municipality itself and the adjacent municipalities surrounding it. A 'migration' is any residential move within the Netherlands that exceeds 40 kilometres. As Goetgeluk (1997) has shown, the majority of moves of 40 kilometres or more in the Netherlands are for work reasons. The variable 'type of migration history' was updated after each migration.

\section{<Figure 3 about here>}

Apart from the classification into types of migration histories, we also use a specification with separate measurements of whether the respondent has ever lived in a city and the number of migrations: one, two (distinguished as return or onward), or more than two.

Since our focus is on the long-term benefits of migration, and we distinguish these from short-term effects, we have controlled for a variable indicating whether the respondent moved at least 40 kilometres in the year of observation or the preceding year.

'Age' was measured in years; 'age squared' was added to allow for non-linearity of the age effect. The variable 'number of years non-employed' measures the number of years the respondent was not employed for reasons other than enrolment in education between age 18 and the year of observation. Even though the respondents were temporarily taken out of the analyses during periods of non-employment, information about past non-employment was included as soon as the respondents returned to paid work. 'Level of education' was measured in four categories: primary or lower; lower 
secondary; higher secondary; and tertiary (higher vocational or university). The measure reflected the highest completed level, and was not updated through time. Two dummies indicate whether there were children in the respondent's household: one indicating whether there was a child under the age of six; the other indicating that the youngest child was aged six or older.

A period variable indicates whether the year of observation was in the period of 1946-1959, 1960-1969, 1970-1979, 1980-1989, or 1990-2000. Experiments with different specifications of the period variable that were supposed to better account for economic booms and busts did not lead to better fitting models or more pronounced parameter estimates for the period effect; neither did the inclusion of the level of unemployment in a given year indicating the economic situation in that year. We did not think this was surprising. The main impact of difficult economic circumstances is probably temporary unemployment, and unemployment spells are not observed. Even though some people might re-enter the labour market in a lower-status job after a period of unemployment, this is probably only a minority. An even better way of accounting for labour market and economic circumstances might have been a region and period specific labour market indicator. Unfortunately, a reliable time-varying labour market indicator at a low spatial level was not available to us. Appendix.

Summary statistics of the dependent and independent variables are given in the

\section{Method}

We have used an OLS regression model in which socio-economic status is the dependent variable. The units of analysis are person-years. For women, we use on average 10.4 person-years per respondent; for men, 18.2 years. This difference between men and women is caused by the fact that it is more common for women to spend time outside the labour market. We estimated the standard errors performing a correction for the clustering of person-years within respondents (Huber, 1967). This was necessary, because the person-years of one respondent are not independent observations. If we had treated them as if they were, we would have obtained far too small standard errors. The correction procedure indeed led to a substantial increase in the standard errors.

'Socio-economic status' was only known for those person-years in which the respondents were employed, so we had to take into account the possibility that the parameter estimates suffered from sample selection bias. We therefore also estimated models using a two-step modelling procedure (compare Heckman, 1979). The first analytical step in this procedure was a probit model of whether the respondent was employed in the given person-year. This model included most of the variables also present in the substantive model together with a variable indicating whether the respondent had a partner and a variable indicating the percentage of people unemployed in the Netherlands in the given year, to identify the model. ${ }^{2}$ The second step was an OLS regression model of socio-economic status that included a correction factor derived from the residuals of the first model. The results of the substantive model in the

\footnotetext{
${ }^{2}$ The best way of identifying the models would be to find variables for the first step that are theoretically related to the variable associated with selection into the sample (employment) but not to the dependent variable in the substantive model (socio-economic status). We could not find any variables for which this was the case undisputedly. We therefore used two variables that were at least empirically not correlated to socio-economic status and for which it could be argued that they were related more to employment than to socio-economic status.
} 
two-step procedure were very similar to those of the simple OLS models, so we have therefore only shown the simple models.

In order to distinguish between the long-term and short-term effects of migration, the models shown include a variable indicating whether the respondent migrated recently. To ascertain the extent to which the parameter estimates for the type of migration history would change without accounting for recent migrations, additional models were estimated that did not include this variable. Because the parameters and significance levels for the type of migration history hardly changed, these models have not been shown.

\section{Results}

Descriptive findings

The most common migration histories are those without any migration or any episode in a large city (Table 1). The second most common histories are also without migration, but with an episode in a city. Almost as common as these are histories with one migration to a city; next come the histories with at least two moves that are all onward. Of the remaining histories, those containing return moves were the least common. The frequencies of types of migration histories pertain to the respondents' last year of observation. It should be noted that a considerable proportion of the histories were truncated before age 60; the average age of the respondents in their last year of observation was 43.5 and the average age in any person-year was around 37 (see Appendix). The frequencies are therefore not indicative of the total histories that people experience during their entire working lives. Because most migrations and most occupational mobility tend to take place at younger ages (Wagner, 1989), however, this under-observation of person-years during older ages is not likely to lead to a similar under-observation of longer migration histories.

<Table 1 about here>

The combination of a high prevalence of histories without an episode in a city and without migration, a low prevalence of histories without an episode in a city but with migration, and a higher prevalence of histories with one migration to a city than with one migration from a city suggests that cities play a major role in migration processes and are major destinations of migration. This is true despite the fact that the respondents spent about two thirds of the time for which they were observed outside large cities (see Table 2).

$<$ Table 2 about here>

\section{Regression results}

There is a marked difference between men and women in the impact of the type of migration history on socio-economic status (Table 3). For men, substantial differences between migration histories in socio-economic status are found, many of which are statistically significant (the significance of the differences between the parameter estimates of all types are shown in Figure 4 for men). For women, the differences are much smaller and none of them reaches significance. A first conclusion from the results, 
therefore, is that, in the long term, men profit more from migrating and from spending time in large cities than women. A similar result is found for the short term. As was also found in previous research, recent migration is positively associated with men's socioeconomic status. For women, a slightly positive but insignificant association is found. So, the common finding that women tend to experience a negative effect of migration in the short run is not replicated in this analysis.

$<$ Table 3 about here>

$<$ Figure 4 about here $>$

For men, a history outside the large cities and without migration (type 1, nomignocity) is associated with a significantly lower socio-economic status than any other history. A history without migration but spent in a large city (type 2, nomigcity) leads to a somewhat higher status than a type 1 history. A history outside the largest cities and with one migration (type 3 , onemigcity) is also more favourable than a type 1 history, but hardly more favourable than a type 2 history. The difference with type 2 is small and insignificant. There seems to be a major division between types 1, 2, and 3 on the one hand and types 4 through 9 on the other. Men with a type 4-9 history (returnnocity, onwardnocity, tocity, fromcity, returncity, onwardcity) have a significantly higher socio-economic status than those with a type 1-3 history, but the differences between pairs of 4-9 histories are small and insignificant. One significant difference was not hypothesised: Type 5 (onwardnocity) is more favourable than type 2 (nomigcity). The picture arising from these findings seems to be as follows. The achievement of a high socio-economic status is favoured by either migration or a period spent in a large city. Experiencing both facilitates the achievement of an even higher status; adding either a migration or a period in a large city is more conducive to high achievement than migration and not having lived in a city. No support was found for the hypothesis that onward migration is more favourable than return migration.

The model with an alternative specification of the migration variables (Table 4) yielded some interesting additional results. For men, we see a significant difference between migrating once and not migrating at all, and between migrating at least three times and migrating once or not at all. Furthermore, a significant impact of ever having lived in a city is found for men. For women, having migrated at least three times is associated with a significantly higher socio-economic status than having migrated once, twice, or not at all. The fact that, for women, migration only seems to start having positive effects after three or more migrations is unexpected. Possibly, the category of women prepared to migrate as often as that is even more selective than the category prepared to migrate once or twice. It is also possible that those women who have migrated three times or more are more frequently those who have made at least one move for their own careers rather than for their husbands' careers. Or, finally, it is possible that, after a greater number of migrations, women start profiting even from tied moves, because the greater experience built up in various jobs at different locations starts to pay off even for a move that was not made for the woman's own career.

The findings for the control variables are largely in line with expectations. Socio-economic status increases with age, but less so as age rises (the maximum of the age effect is estimated at age 57.9 for men and age 55.1 for women: this result was obtained from a parameter estimate with 7 rather than 3 digits behind the decimal 
point). The impact of the number of non-employed years is negative, but more so for men than for women. 'Level of education' is positively associated with socio-economic status for both men and women. For women, a negative impact is found of the presence of children in the household. This impact is stronger when the children are older than when they are below school age. This finding suggests a cumulative impact of years spent in part-time work (note that the impact of years spent outside the labour force should be captured by the variable 'years non-employed'). The period effect seems to suggest that it has become more difficult to reach a higher socio-economic status through the past few decades. This result is caused by changes through time in the composition of the population with regard to other variables in the model, particularly educational expansion. Before controlling for level of education, the period effect was small and not statistically significant (result not shown). So, although reaching a certain socio-economic status does not seem to have become more difficult in general terms, it does seem to be harder with a given level of education.

\section{Conclusions and discussion}

In this paper, we have investigated the impact of migration histories on occupational achievement. This allowed us to address not only the long-term versus the short-term impact of migration, but also the impact of having lived in a large city, having moved once versus more than once, and making return versus onward moves.

Support was found for the hypothesis that migration has a positive long-term impact on men's occupational achievement. Only multiple migrations (three or more) affect women's occupational achievement significantly, in a positive way. This finding is in line with previous findings indicating that a negative short-term impact of migration for women tends to fade within a few years after the move. The existence of such a short-term negative impact of migration for women was not confirmed in this study. It should be noted, however, that periods of non-employment were not included in the analyses. So, any negative short-term impacts in the form of a temporary retreat from the labour force did not show up. For men, we did find a positive short-term impact of migration.

The hypothesis stating that histories including a stay in a large city would be beneficial to occupational achievement was also supported for men but not for women. Less support was found for the idea that histories with a greater variety of regions would lead to better occupational achievement. Even though indications were found that additional migrations were positively associated with occupational achievement, the expected difference between onward and return migration was not found. It should be noted, however, that there were only a few hundred person-years of people having histories including return migration, so further research using larger datasets might yield more conclusive results.

The near-absence of an impact of migration histories on women's occupational achievement can be interpreted in two ways. On the one hand, it is reassuring that there was no indication whatsoever of a negative long-term impact. Apparently, many women are capable of overcoming possible short-term impacts of migration, or a negative impact for some of the women may be counterbalanced by a positive impact for others. On the other hand, women are apparently much less likely than men to succeed in using migration to promote their occupational careers. 
Migration histories can hardly be seen as causes of occupational achievement. Rather, migration is an instrument for investing in occupational careers (compare Sjaastad's classical argument). This statement is only true, however, for those who migrate for the sake of their own careers (probably mostly men). It is not true for those who migrate for the benefit of someone else (probably mostly women).

Our aim was to establish whether migration was associated with occupational achievement, not whether a similar occupational achievement would have been reached had exactly the same persons not migrated. We therefore did not try to correct for the self-selectivity of migrants. As a consequence, our regression models are, strictly speaking, not causal. They should instead be interpreted as sophisticated descriptive statistics.

\section{Acknowledgement}

Maarten van Ham contributed to this paper while being a member of the Department of Geography, Planning and International Development Studies of the University of Amsterdam.

\section{References}

Aassve A, Mazzuco S, Mencarini L. 2003. Household formation among young adults and implications for poverty dynamics: A comparative analysis based on ECHP. In paper presented at the EURESCO conference " The second demographic transistion". Spa.

Bailey AJ, Cooke TJ. 1998. Family migration and employment: The importance of migration history and gender. International Regional Science Review 21: 99-118.

Blau PM, Duncan OD. 1967. The American occupational structure. Wiley: New York.

Bonney N, Love J. 1991. Gender and migration: Geographical mobility and the wife's sacrifice. The Sociological Review 39: 335-348.

Clark WAV, Davies Withers S. 2002. Disentangling the interaction of migration, mobility, and labor-force participation. Environment and Planning A 34: 923-945.

Cooke TJ, Bailey AJ. 1996. Family migration and the employment of married women and men. Economic Geography 72: 38-48.

Cooke TJ, Bailey AJ. 1999. The effect of family migration, migration history, and selfselection on married women's labour market achievement. In Migration and gender in the developed world, Boyle P, Halfacree K (eds.). Routledge: London; 102-113.

Cooke TJ. 2003. Family migration and the relative earnings of husbands and wives. Annals of the Association of American Geographers 93: 338-349.

DaVanzo J. 1981. Repeat migration, information costs, and location-specific capital. Population and Environment 4: 45-73.

Fagan C, Rubery J. 1996. The salience of the part-time divide in the European Union. European Sociological Review 12: 224-250.

Fielding AJ. 1992. Migration and social mobility: South East England as an escalator region. Regional Studies 26: 1-15.

Ganzeboom HBG, De Graaf P, Treiman DJ. 1992. A standard international socioeconomic index of occupational status. Social Science Research 21: 1-56.

Goetgeluk R. 1997. Bomen over wonen. Woningmarktonderzoek met beslissingsbomen. 
(Trading off housing preferences. Housing market research with decision plan nets.) Utrecht University (research thesis): Utrecht.

Heckman J. 1979. Sample selection bias as a specification error. Econometrica 47: 153161.

Huber PJ. 1967. The behavior of maximum likelihood estimates under nonstandard conditions. In Proceedings of the fifth Berkeley Symposium on Mathematical Statistics and Probability. University of California Press: Berkeley, CA; 221-233.

Jacobsen JP, Levin LM. 1997. Marriage and migration: Comparing gains and losses from migration for couples and singles. Social Science Quarterly 78: 688-709.

LeClere FB, McLaughlin DK. 1997. Family migration and changes in women's earnings: A decomposition analysis. Population Research and Policy Review 16: 315-335.

Lelièvre E, Bonvalet C. 1994. A compared cohort history of residential mobility, social change and home-ownership in Paris and the rest of France. Urban Studies 31: 1647-1665.

Morrison PA. 1971. Chronic movers and the future redistribution of population: a longitudinal analysis. Demography 8: 171-184.

Newbold KB. 1996. Income, self-selection and return and onward interprovincial migration in Canada. Environment and Planning A 28: 1019-1034.

Simpson W. 1992. Urban structure and the labour market: worker mobility, commuting and underemployment in cities. Clarendon Press: Oxford.

Sjaastad LA. 1962. The costs and returns of human migration. Journal of Political Economy 70: 80-93.

Smits J. 2001. Career migration, self-selection and the earnings of married men and women in the Netherlands, 1981-93. Urban Studies 38: 541-562.

Smits J, Mulder CH, Hooimeijer P. 2003. Changing gender roles, shifting power balance, and long-distance migration of couples. Urban Studies 40: 603-613.

Spitze G. 1984. The effect of family migration on wives' employment: How long does it last? Social Science Quarterly 65: 21-36.

Topel RH, Ward MP. 1992. Job mobility and the careers of young men. Quarterly Journal of Economics 107: 439-479.

Ultee WC, Ganzeboom HBG. 1993. Netherlands Family Survey 1992-93 [machine readable data set]. Codebook prepared by Harry B.G. Ganzeboom, Susanne Rijken, September 1993 edition. Changes and additions made by Harry B.G. Ganzeboom and Roland Weygold, January 1995 edition. Dept. of Sociology, Nijmegen University: Nijmegen, Netherlands.

Van Ham M. 2002. Job access, workplace mobility, and occupational achievement. Eburon: Delft.

Van Ham M. 2003. Job access at labour market entry and occupational achievement in the life course. International Journal of Population Geography 9: 387-398.

Wagner M. 1989. Spatial determinants of social mobility: An analysis with life history data for three West German cohorts. In Migration and Labor Market Adjustment, Van Dijk J, Folmer H, Herzog HW, Schlottman AM (eds.). Kluwer Academic: Dordrecht; 241-264. 
Figure 1. Nine types of migration histories.

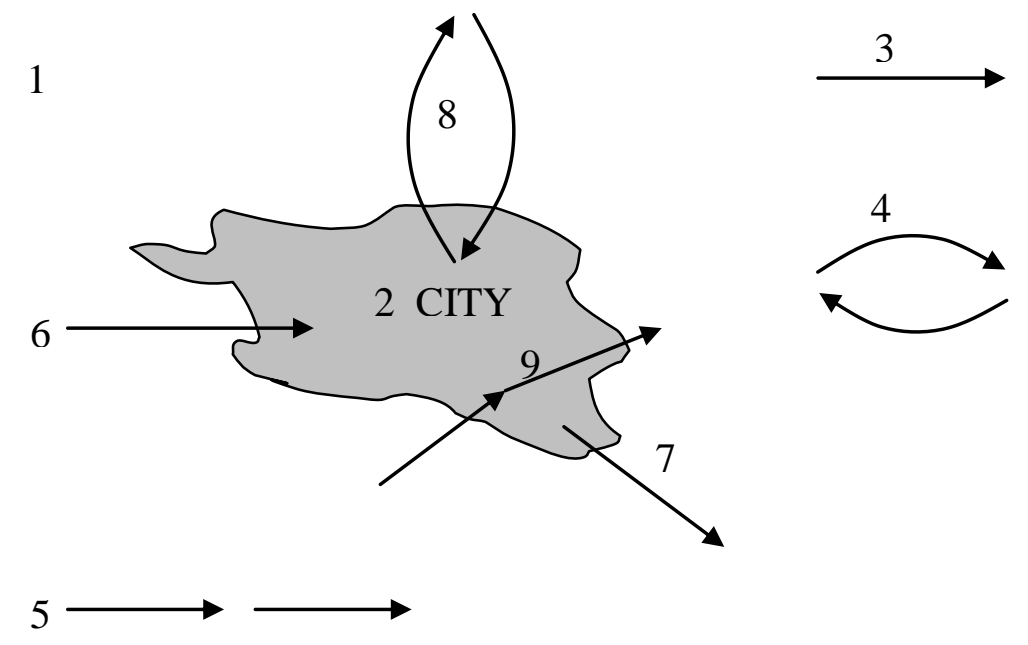

1. No migration, no episode in city (Nomignocity)

2. No migration, episode in city (Nomigcity)

3. 1 migration, no episode in city (Onemignocity)

4. Return migration, no episode in city (Returnnocity)

5. Onward migration, no episode in city (Onwardnocity)

6. 1 migration to city (Tocity)

7. 1 migration from city (Fromcity)

8. Return migration, episode in city (Returncity)

9. Onward migration, episode in city (Onwardcity) 
Figure 2. Summary of hypotheses.

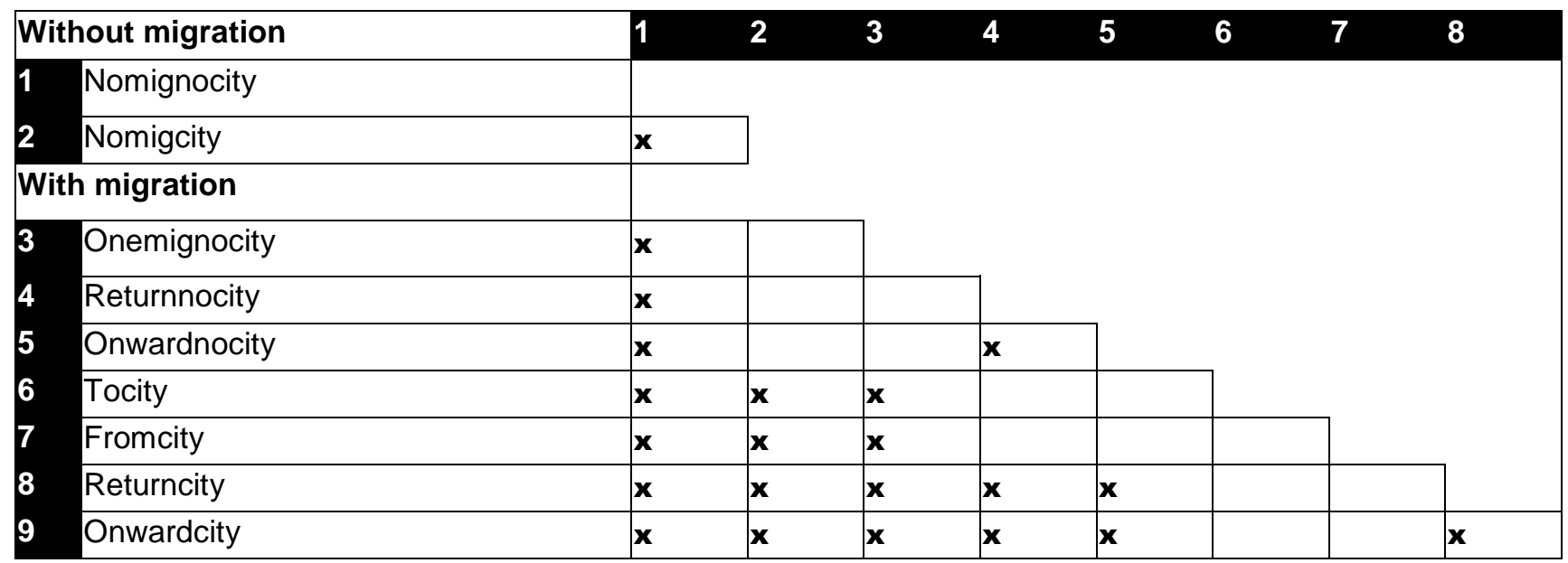

$\mathbf{x}$ Types mentioned in rows (1 through 9) are hypothesised to lead to better occupational achievement for men than types referred to in columns (1 through 8). 
Figure 3. Eight agglomerations in the Netherlands.

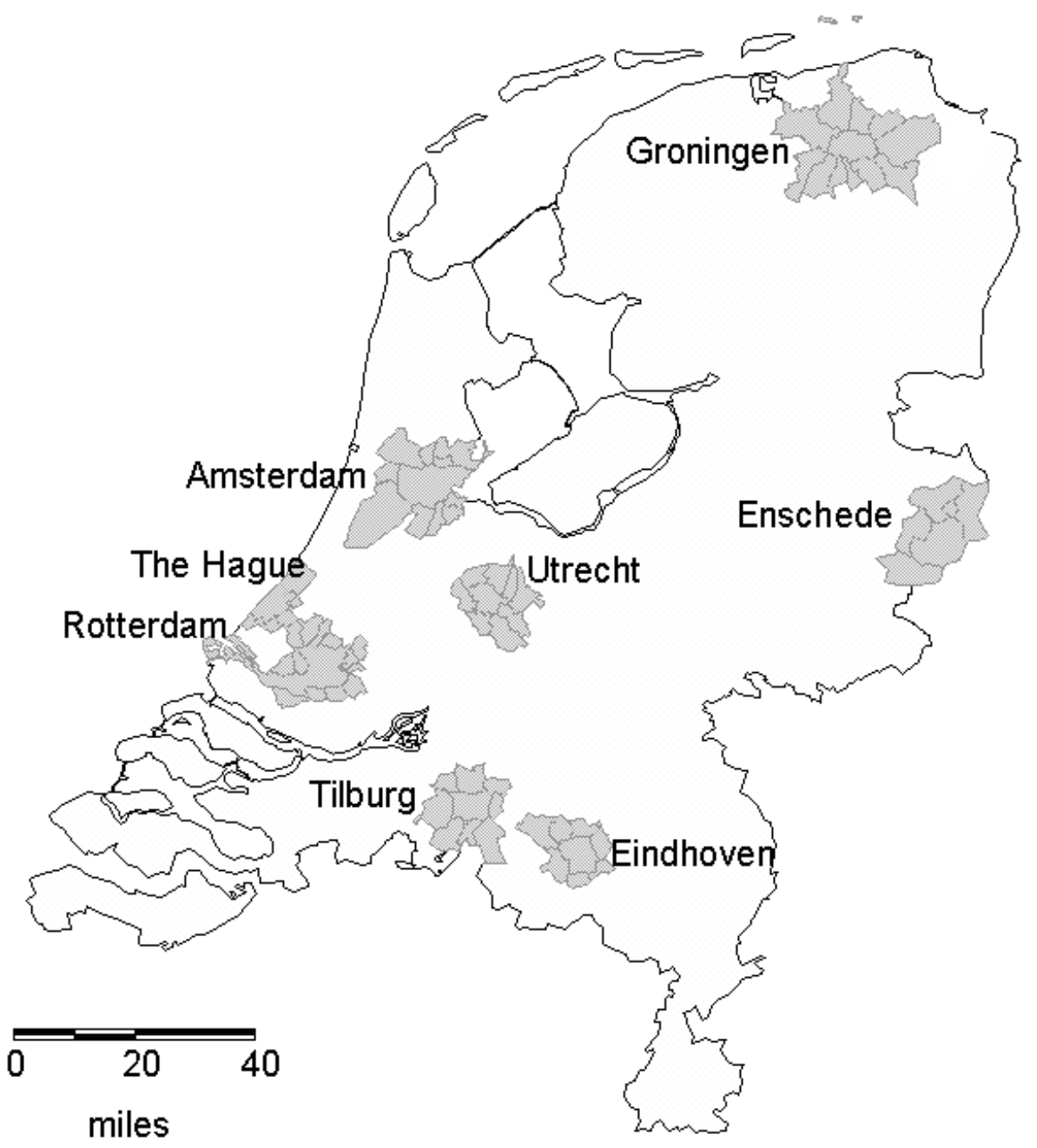


Figure 4. Significance of differences between parameters for men from Table 3.

\begin{tabular}{|c|c|c|c|c|c|c|c|c|}
\hline & \multicolumn{8}{|c|}{ Differences between types of migration histories } \\
\hline Without migration & 1 & 2 & 3 & 4 & 5 & 6 & 7 & 8 \\
\hline $1 \quad$ Nomignocity & & & & & & & & \\
\hline 2 Nomigcity & $++^{* \star}$ & & & & & & & \\
\hline With migration & & & & & & & & \\
\hline Onemignocity & $+{ }^{*}$ & + & & & & & & \\
\hline Returnnocity & $+^{* \star}$ & + & + & & & & & \\
\hline Onwardnocity & $+^{\star \star \star}$ & $++^{* * *}$ & $+{ }^{* *}$ & + & & & & \\
\hline Tocity & $++^{\star \star \star}$ & $+t^{* * *}$ & $+{ }^{* *}$ & - & - & & & \\
\hline Fromcity & $+^{* \star *}$ & $+{ }^{* *}$ & + & - & - & - & & \\
\hline Returncity & $+^{\star \star \star}$ & $+^{\star * \star}$ & $+{ }^{* *}$ & + & + & + & + & \\
\hline 9 Onwardcity & $+^{* \star *}$ & $+^{* \star *}$ & $+{ }^{* *}$ & - & - & + & + & + \\
\hline
\end{tabular}

+ type in row is associated with better occupational achievement than type in column; - type in row is associated with better occupational achievement than type in column. $* p<0.10 ; * * p<0.05 ; * * * p<0.01$ 
Table 1. Frequencies of types of migration history (last person-year per respondent)

\begin{tabular}{llll} 
& $\begin{array}{l}\text { all } \\
\%\end{array}$ & $\begin{array}{l}\text { males } \\
\%\end{array}$ & $\begin{array}{l}\text { females } \\
\%\end{array}$ \\
\hline Nomignocity & 36.7 & 36.9 & 36.5 \\
Nomigcity & 19.7 & 19.3 & 20.0 \\
Onemignocity & 5.4 & 5.4 & 5.4 \\
Returnnocity & 0.6 & 0.7 & 0.5 \\
Onwardnocity & 4.2 & 3.9 & 4.4 \\
Tocity & 18.4 & 18.2 & 18.6 \\
Fromcity & 5.2 & 5.0 & 5.3 \\
Returncity & 1.1 & 1.0 & 1.1 \\
Onwardcity & 8.8 & 9.4 & 8.1
\end{tabular}

Number of respondents $\quad 38092002 \quad 1807$ 
Table 2. Frequencies of person-years spent in large cities and outside large cities

\begin{tabular}{llll} 
& all & males & females \\
$\%$ & $\%$ & $\%$ \\
\hline Lived in agglomeration & 32.3 & 32.4 & 32.0 \\
Did not live in agglomeration & 67.6 & 67.4 & 67.9 \\
Number of person years & 39471 & &
\end{tabular}


Table 3. Regression results

Males Females

\begin{tabular}{|c|c|c|c|c|c|c|}
\hline \multirow{2}{*}{\multicolumn{7}{|c|}{$\begin{array}{l}\text { Coeff. } \\
\text { Type of migration history Nomignocity }=0 \text { ) }\end{array}$}} \\
\hline & & & & & & \\
\hline Nomigcity & 0.183 & 0.085 & ** & 0.068 & 0.119 & \\
\hline Onemignocity & 0.262 & 0.142 & * & 0.117 & 0.208 & \\
\hline Returnnocity & 0.708 & 0.328 & ** & 0.096 & 0.377 & \\
\hline Onwardnocity & 0.766 & 0.164 & *** & 0.138 & 0.122 & \\
\hline Tocity & 0.610 & 0.091 & $* \star *$ & 0.134 & 0.117 & \\
\hline Fromcity & 0.484 & 0.142 & *** & 0.225 & 0.154 & \\
\hline Returncity & 0.799 & 0.189 & $* * *$ & -0.058 & 0.336 & \\
\hline Onwardcity & 0.637 & 0.118 & $* * *$ & 0.162 & 0.166 & \\
\hline Migrated in last 2 years & 0.204 & 0.067 & $\star \star \star *$ & 0.073 & 0.096 & \\
\hline Age & 0.066 & 0.015 & $\star \star \star *$ & 0.088 & 0.024 & $* * *$ \\
\hline Age squared & -0.001 & 0.000 & *** & -0.001 & 0.000 & $* * *$ \\
\hline Number of years non-employed & -0.039 & 0.019 & $* *$ & -0.017 & 0.009 & * \\
\hline \multicolumn{7}{|l|}{ Level of education (Primary $=0$ ) } \\
\hline Lower secondary & 0.382 & 0.103 & *** & 0.337 & 0.144 & ** \\
\hline Upper secondary & 0.790 & 0.111 & *** & 0.854 & 0.154 & *** \\
\hline Tertiary & 2.013 & 0.110 & *** & 1.927 & 0.155 & *** \\
\hline \multicolumn{7}{|c|}{ Age of youngest child (No children $=0$ ) } \\
\hline Under 6 years old & 0.061 & 0.052 & & -0.223 & 0.076 & *** \\
\hline 6 years or older & 0.015 & 0.082 & & -0.489 & 0.121 & *** \\
\hline \multicolumn{7}{|l|}{ Period $(1946-1959=0)$} \\
\hline $1960-1969$ & -0.083 & 0.084 & & -0.105 & 0.133 & \\
\hline $1970-1979$ & -0.176 & 0.105 & * & -0.244 & 0.144 & * \\
\hline 1980-1989 & -0.245 & 0.118 & ** & -0.215 & 0.154 & \\
\hline $1990-2000$ & -0.287 & 0.126 & ** & -0.319 & 0.168 & * \\
\hline Constant & 2.382 & 0.295 & $* * *$ & 2.402 & 0.464 & $* * *$ \\
\hline Number of respondents & 1831 & & & 1357 & & \\
\hline Number of person-years & 33357 & & & 14173 & & \\
\hline $\mathrm{F}$ & 56.1 & & & 18.5 & & \\
\hline$d f, p$ & $1830,0.00$ & & & $1356,0.00$ & & \\
\hline R-squared & 0.30 & & & 0.26 & & \\
\hline
\end{tabular}

${ }^{*} p<0.10 ;{ }^{* *} p<0.05 ;{ }^{* * *} p<0.01$ 
Table 4. Regression results with alternative specification of migration histories

$$
\text { Males Females }
$$

\begin{tabular}{|c|c|c|c|c|c|c|}
\hline & Coeff. & Std.Error & & Coeff. & Std.Error & \\
\hline Ever lived in agglomeration & 0.190 & 0.067 & $* * *$ & 0.054 & 0.091 & \\
\hline \multicolumn{7}{|c|}{ Number of migrations $(0$ migrations $=0$ ) } \\
\hline 1 migration & 0.287 & 0.088 & $* * *$ & 0.111 & 0.118 & \\
\hline 2 migrations, onward & 0.334 & 0.101 & $* * *$ & -0.065 & 0.143 & \\
\hline 2 migrations, back & 0.564 & 0.219 & $* *$ & -0.246 & 0.268 & \\
\hline 3 migrations or more & 0.789 & 0.121 & $* * *$ & 0.402 & 0.150 & $* * *$ \\
\hline Migrated in last 2 years & 0.133 & 0.066 & $* *$ & 0.033 & 0.098 & \\
\hline Number of respondents & 1831 & & & 1357 & & \\
\hline Number of person years & 33322 & & & 14172 & & \\
\hline $\mathrm{F}$ & 65.3 & & & 22.7 & & \\
\hline$d f, p$ & $1830,0.00$ & & & $1356,0.00$ & & \\
\hline R-squared & 0.31 & & & 0.26 & & \\
\hline
\end{tabular}

${ }^{*} p<0.10 ;{ }^{* *} p<0.05 ;{ }^{* * *} p<0.01$

Control variables:

Age, Age squared, Number of years non-employed, Level of education, Age youngest child, Period (parameters not shown) 
Appendix: Frequencies (means) of dependent and independent variables

\begin{tabular}{|c|c|c|c|c|c|c|}
\hline & \multicolumn{2}{|l|}{ All } & \multicolumn{2}{|l|}{ Males } & \multicolumn{2}{|l|}{ Females } \\
\hline & $\%$ (means) & std. dev. & $\%$ (means) & std. dev. & $\%$ (means) & std. dev. \\
\hline ISEI of current job (means) & 4.91 & 1.58 & 4.94 & 1.58 & 4.83 & 1.56 \\
\hline Sex: Female & 29.8 & & & & & \\
\hline \multicolumn{7}{|l|}{ Type of migration history } \\
\hline Nomignocity & 36.1 & & 37.4 & & 33.1 & \\
\hline Nomigcity & 22.0 & & 21.8 & & 22.5 & \\
\hline Onemignocity & 5.1 & & 4.8 & & 5.7 & \\
\hline Returnnocity & 0.6 & & 0.7 & & 0.5 & \\
\hline Onwardnocity & 3.8 & & 3.9 & & 3.8 & \\
\hline Tocity & 18 & & 16.9 & & 20.7 & \\
\hline Fromcity & 4.8 & & 4.7 & & 5.2 & \\
\hline Returncity & 1.0 & & 1.1 & & 0.8 & \\
\hline Onwardcity & 8.5 & & 8.8 & & 7.7 & \\
\hline Ever lived in agglomeration & 54.3 & & 53.2 & & 56.9 & \\
\hline Lives in agglomeration now? & 32.1 & & 32.3 & & 32.4 & \\
\hline Migrated in last 2 years & 4.0 & & 96.0 & & 96.1 & \\
\hline \multicolumn{7}{|l|}{ Number of migrations } \\
\hline 0 migrations & 63.8 & & 64.7 & & 61.6 & \\
\hline 1 migration & 15.6 & & 14.4 & & 18.6 & \\
\hline 2 migrations, onward & 10.6 & & 10.5 & & 10.9 & \\
\hline 2 migrations, back & 1.3 & & 1.4 & & 1.0 & \\
\hline 3 migrations or more & 8.7 & & 9.0 & & 7.9 & \\
\hline Age (means) & 37.02 & 8.84 & 37.4 & 8.89 & 36.2 & 8.66 \\
\hline \multicolumn{7}{|l|}{ Level of education } \\
\hline Primary & 13.8 & & 13.6 & & 14.0 & \\
\hline Lower secondary & 37.2 & & 36.7 & & 38.3 & \\
\hline Upper secondary & 23.3 & & 23.9 & & 22.0 & \\
\hline Tertiary & 25.7 & & 25.7 & & 25.7 & \\
\hline Number of years non-employed & 1.48 & 3.75 & 0.59 & 1.76 & 3.57 & 5.80 \\
\hline \multicolumn{7}{|c|}{ Age group youngest child } \\
\hline No children & 35.3 & & 32.9 & & 40.9 & \\
\hline Under 6 years old & 23.1 & & 25.4 & & 17.7 & \\
\hline 6 or older & 41.6 & & 41.7 & & 41.4 & \\
\hline \multicolumn{7}{|l|}{ Period } \\
\hline 1946-1959 & 4.8 & & 5.3 & & 3.6 & \\
\hline $1960-1969$ & 11.3 & & 12.7 & & 8.1 & \\
\hline $1970-1979$ & 23.6 & & 24.6 & & 21.3 & \\
\hline 1980-1989 & 37.8 & & 36.6 & & 40.7 & \\
\hline $1990-2000$ & 22.5 & & 20.9 & & 26.3 & \\
\hline
\end{tabular}

